\title{
BCG terapéutica por vía percutánea en el tratamiento del carcinoma urotelial múltiple de vía superior
}

J. Palou Redorta, A.M. Autran, R.H. Martínez Rodríguez, Jorge Huguet Pérez, A. Rosales Bordes, H. Villavicencio Mavrich

Servicio de Urología Fundació Puigvert. Barcelona.

Actas Urol Esp 2005; 29(8): 787-790

\section{RESUMEN}

BCG TERAPÉUTICA POR VÍA PERCUTÁNEA EN EL TRATAMIENTO DEL CARCINOMA UROTELIAL MÚLTIPLE DE VÍA SUPERIOR

El tumor urotelial del tracto urinario superior constituye un tipo de tumor de baja prevalencia, frecuentemente asociado a tumor vesical. El uso de la vía endoscópica con acceso anterógrado representa un método de tratamiento seguro, eficaz y mínimamente invasivo. La asociación con inmunoterapia parece efectiva para disminuir la recurrencia. Presentamos un caso de tumor de tramo urinario superior múltiple tratado mediante exéresis percutánea e inmunoterapia terapéutica

Palabras clave: Tumor tramo urinario superior; Nefroscopia percutánea; BCG.

ABSTRACT

PERCUTANEOUS TREATMENT WITH BCG IN MULTIPLE UPPER TRACT TRANSITIONAL CELL CARCINOMA

Upper tract transitional cell carcinoma is a low prevalent tumour and frequently associated to bladder carcinoma. The antegrade endoscopic access represents a safe, efficient and minimally invasive access. The association to immunotherapy seems effective in decreasing recurrence. We present one patient with multiple upper tract carcinoma treated with percutaneous surgery and BCG.

Keywords: Upper tract tumour, nephroscopy, BCG.

El uso de la vía endoscópica, con acceso anterógrado, para el tratamiento del tumor urotelial del tramo urinario superior, constituye un enfoque terapéutico aceptado en el tratamiento de tumor del tracto urinario superior ${ }^{1-3}$.

A pesar de presentar un tumor multifocal y la situación del paciente como monorreno, una indicación imperativa con resección lo más amplia posible percutánea más una terapia adyuvante tópica puede permitir una preservación renal.

\section{CASO CLÍNICO}

Paciente varón de 55 años, con antecedentes de hipertensión arterial y accidente vascular cerebral en 1955. En agosto del 2002 acudió al servicio de urgencias por episodio de hematuria. Se realizó urografía intravenosa que revelaba: Riñón derecho no funcionante y riñón izquierdo con imágenes de ocupación a nivel de la pelvis renal, compatible con tumor urotelial, (Fig.1). Se completó estudio mediante TAC observando ureterohidronefrosis secundaria a obstrucción por tumor de vías a nivel del tercio medio-distal de ureter derecho, y ocupación de pelvis renal izquierda e infundíbulos calicilares (Fig. 2).

Fue sometido a Nefrouretectomía derecha con desinserción endoscópica del meato ureteral derecho. La anatomía patológica reveló un tumor localizado a nivel de la pelvis renal y tercio medio distal de uréter derecho identificado como Car- 


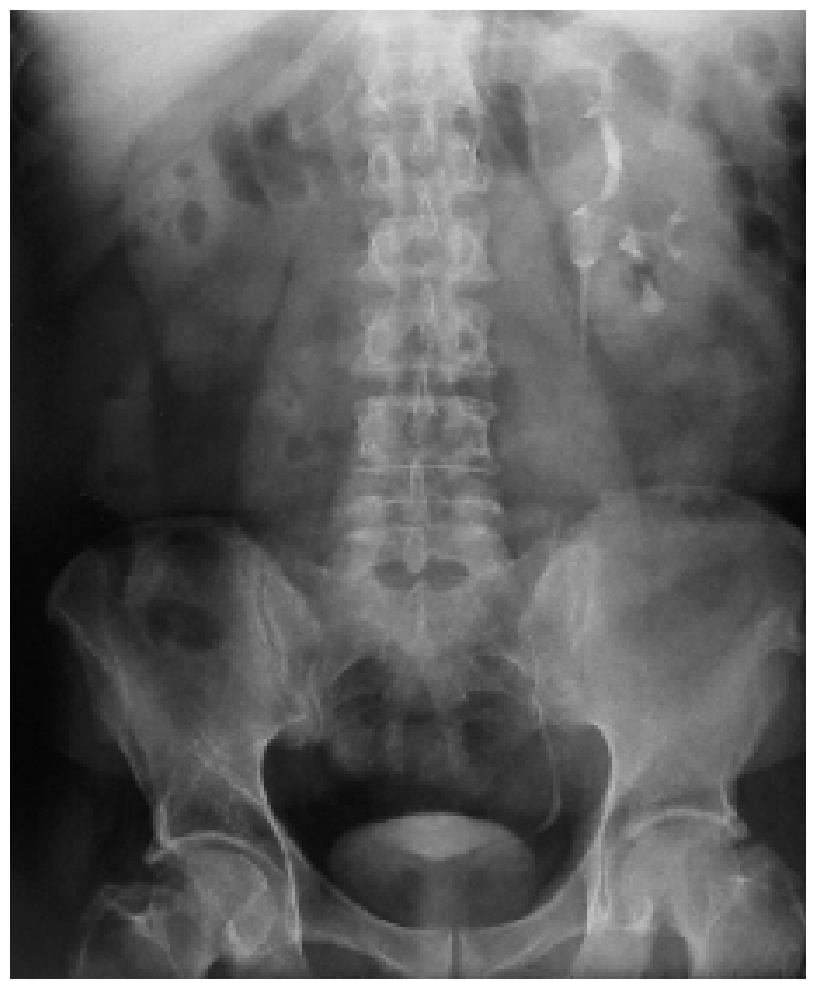

FIGURA 1. Urografia intravenosa. Riñón derecho, no funcionante y riñón izquierdo con imágenes de ocupación a nivel de la pelvis renal, compatible con tumor urotelial.

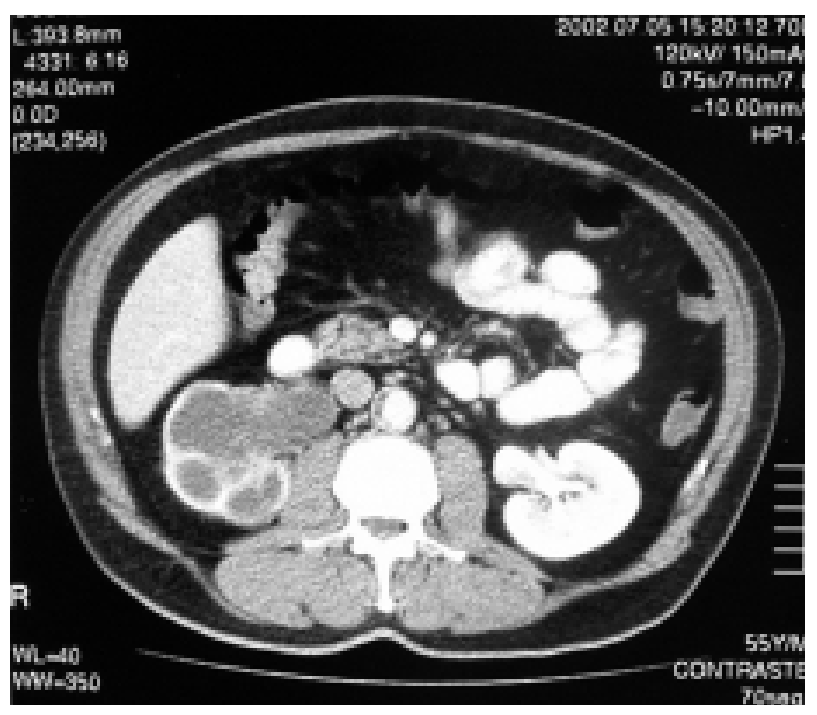

FIGURA 2. TAC de abdomen. Destaca una uropatia obstructiva derecha con ureterohidronefrosis. Lesión que capta contraste y que ocasiona defecto de replección localizada en la porción inferior de la pelvis renal izquierda.

cinoma urotelial multicéntrico, con patrón papilar Grado 2-3 acompañado de focos de diferenciación escamosa que infiltraba el tejido conectivo subepitelial. (PT1 G2-3 Nx).
El paciente fue remitido a nuestro centro para realizar una valoración del tumor piélico-calicilar izquierdo. En diciembre del 2002 , se efectuó la exéresis de la neoformaciòn pielica izquierda, por vía percutánea, con resección incompleta de la lesión a nivel del càliz medio. La anatomía patológica demostró un Carcinoma urotelial con patrón papilar G2 que infiltraba tejido conectivo subepitelial (G2 TA). Recibió instilaciones de BCG Conaught $(81 \mathrm{mg})$ a través de la nefrostomía, a una velocidad de $50 \mathrm{ml}$ por hora. Recibió sólo 3 instilaciones debido a la aparición de cuadro febril.

En Febrero 2002 se efectuó ecografía renovesical de control, no evidenciándose alteraciones. En el cultivo de orina obtenida por sonda de nefrostomía se aisló Klebsiella Oxytoca, sensible a ciprofloxacino, iniciando tratamiento antimicrobiano adecuado.

La pielografía anterógrada de control en abril del 2003 demostró un defecto de replección a nivel piélico (Fig. 3), por lo que se efectuó nefroscopia percutánea en mayo del mismo año, evidencian-

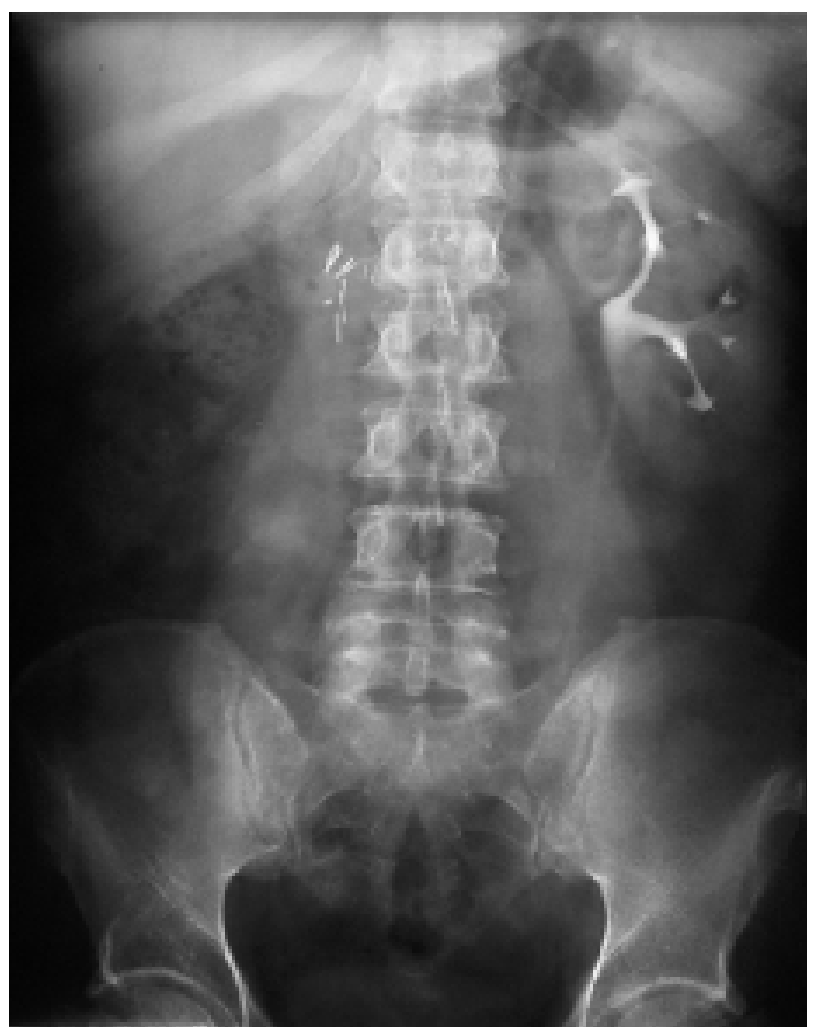

FIGURA 3. Pielografia anterógrada de control. Ausencia de tumor. 
do áreas de apariencia pseudotumoral de aspecto papilar de aproximadamente $1 \mathrm{~cm}$ de superficie que se biopsiaron. Fueron informadas como agregados epiteliales atípicos con tejido de granulación, recubierto por urotelio reactivo.

Desde entonces el paciente ha sido controlado ambulatoriamente y no se evidencia recidiva tumoral.

\section{DISCUSION}

Dentro de los tumores del tracto urinario superior, los uroteliales ocupan aproximadamente un $5 \%$, siendo del $82-87 \%$ de origen transicional $^{1,2}$. Pueden tener un comportamiento multifocal en un $6-25 \%$ de los casos. Su bilateralidad sincrónica es rara, siendo más frecuente la aparición metacrónica en un 1-3\%.La localización más frecuente es a nivel pielocalicial $(75 \%)$. La presencia de un tumor vesical concomitante metacrónico puede ocurrir hasta en un $24 \%$ de los casos, con un tiempo medio de aparición de aproximadamente 18 meses. ${ }^{2}$.

Es conocido que la progresión y recurrencia de los tumores uroteliales están relacionados con múltiples factores como el grado, el estadio, localización, tamaño y multiplicidad de las lesiones ${ }^{4}$. Martínez-Piñeiro y cols ${ }^{5}$ sobre la base de 59 casos de Tumor de tramo urinario superior (TUTS) en pacientes sin tumor vesical previo describieron una tasa de recidivas en torno al 16.6\% .De los pacientes que presentaron recurrencia un $80 \%$ tenían asociado tumor vesical.

Vest en 1945 y Ferris Dault en $1948^{3}$, fueron los primeros en proponer el uso de la cirugía conservadora. En esta línea, Murphy et $\mathrm{al}^{3}$ publicó los resultados de una serie de 224 pacientes donde, para los tumores Grado 1, la supervivencia era independiente de la total o parcial extirpación del tracto urinario superior. Según Mazeman, Ziegelbaum, y Zincke $^{3}$ existe un 23$30 \%$ de recurrencia tras el empleo de cirugía conservadora abierta.

Huffman y cols en $1985^{6}$ propugnan el uso de técnicas endoscópicas para el tratamiento de los tumores del tramo urinario superior. Existe un riesgo de recurrencia con el uso de una técnica conservadora y endoscópica (acceso anterógrado o acceso retrógrado).
Serrano Pascual y cols ${ }^{7}$ evidencian en una revisión extensa bibliográfica que el acceso anterógrado es una técnica segura y eficaz, que no comporta un riesgo significativo de diseminación, siempre y cuando se adopten una serie de precauciones para evitar dicha complicación ${ }^{7}$.

En la serie de Palou y cols ${ }^{8}$ con 34 pacientes tratados mediante vía percutánea obtuvieron una recurrencia del $41,2 \%$ con preservación renal del $73,5 \%$, y sólo 2 pacientes murieron por la enfermedad.

En cuanto al empleo de la inmunoterapia y quimioterapia como tratamiento adyuvante en TUTS, se han establecido diversos protocolos con BCG, Mitomicina C, y Tiotepa. Martínez Piñeiro y $\operatorname{cols}^{9}$ publicaron el resultado de un estudio de 13 años de experiencia en el manejo de TUTS, instilando $150 \mathrm{mg}$ de BCG (Pasteur) ó $81 \mathrm{mg}$ de BCG (Connaught) en $250 \mathrm{ml}$ de sol. fisiológica $0,9 \%$ con tiempo de infusión de 3 horas a 55 gotas por minuto, semanalmente durante 3 semanas. Clark ${ }^{10}$, describió el uso de $50 \mathrm{mg}$ BCG (Tice) diluida en $50 \mathrm{cc}$ de sol. fisiológica $9 \%$ a pasar a $50 \mathrm{ml} / \mathrm{h}$, pinzando posteriormente la nefrostomía, repitiendo semanalmente por 6 semanas. Martínez Piñeiro y cols ${ }^{9}$ describe un menor porcentaje de recurrencia con el uso de BCG o Mitomycina C en relación a aquellos que fueron tratados con Thiotepa. Jabour y Smith ${ }^{1}$ reportan menor porcentaje de recurrencia en pacientes Grado I, tratados con BCG por vía percutánea. Asimismo, recientemente Thalmann y cols han presentado la utilización de la BCG terapéutica en pacientes con citología positiva o tumor del tramo urinario superior no candidatos a cirugía radical, con buenos resultados, sobretodo en los casos de carcinoma "in situ".

Existe escasa experiencia con la inmunoterapia o quimioterapia , como tratamiento adyuvante para la eliminación del tumor residual, después de la extracción percutánea. Dada la experiencia en vejiga, en la erradicación de tumor centinela ${ }^{10-} 12$ esta terapéutica puede ser utilizada en tracto urinario superior en casos muy seleccionados. En este paciente con enfermedad residual macroscópica evidente, la instilación de BCG percutánea, permitió la erradicación completa del tumor. 


\section{CONCLUSIONES}

El uso de la vía endoscópica con acceso anterógrado, para el tratamiento del tumor urotelial del tracto urinario superior, representa un método seguro, eficaz y mínimamente invasivo. Se requiere de un seguimiento estricto y a largo plazo. En cuanto al uso de la inmunoterapia, parece efectiva para disminuir la recurrencia. Puede ser utilizado como tratamiento adyuvante con tumor residual en casos muy seleccionados.

\section{REFERENCIAS}

1. Jabour M, Smith A. Primary percutaneous approach to upper urinary tract transitional cell carcinoma. Urol Clinic North Am 2000;27:739,

2. Vicente J, Laguna P, Palou J. Transitional cell carcinoma in the upper urinary tract: Diagnosis and management. Urol Int 1995;1:7.

3. Pérez P, García R, García E, Lovaco F. Tumor de urotelio de via superior, manejo endoscopico anterogrado. Arch Esp Urol 2004;57(3):265-281.

4. Palou J, Rosales A, Ribal MJ, Vicente J, Salvador J, Villavicencio $H$. Valoración global de los resultados del tratamiento del carcinoma urotelial mediante ureterorenoscopia. Arch Esp Urol 2004;57(3):299-302.

5. Martínez-Piñeiro JA, García MJ, Martínez-Piñeiro L. Endourological treatment of upper tract urothelial carcinoms: analysis of a series of 59 tumours. J Urol 1996;156: 377.

6. Huffman JL, Bagley DH, Lyon ES. Endoscopic diagnosis and treatment of upper tract urothelial tumours. A preliminary report. Cancer 1985;55:1422.
7. Serrano P, Fernàndez I, Gonzàlez-Peramonto P, García R; Lovaco F. Existe riesgo de diseminaciòn del carcinoma en el acceso anterógrado del tratamiento endoscopico del tumor de urotelio superior. Arch Esp Urol 2004;57(3):283290.

8. Palou J, Piovesan LF, Huguet J, Salvador J, Vicente J, Villavicencio H. Percutaneous nephroscopic management of upper urinary tract transicional cell carcinoma recurrente and long-term followup. J Urol 2004 Jul;172(1):6669.

9. Martínez-Piñeiro JA. 13 year experience with percutaneous management of upper tract transitional cell carcinoma J Urol 1999;161:775.

10. Clark P, Streem S, Geisinger M. 13 year experience with percutaneous management of upper tract transitional cell carcinoma. J Urol 1999;161:772.

11. Van Der Meijden AP, Hall RR, Kurth KH, Bouffioux C, Sylvester R. Phase II trials in Ta, T1 bladder cancer. The marker tumour concept. Brit J Urol 1996;77 (5):634-637.

12. Bono Av, Hall Rr, Denis L, Lovisolo JA, Sylvester R. Chemoresection in Ta-T1 Bladder cancer. Eur Urol 1996;29(4): 385-390.

13. Fellows GJ, Parmar MKB, Grigor KM, Hall RR, Heal MR, Wallace DM. Tumor response to evans and Pasteur bacille Calmette-Guérin in multiple recurrent pTa/pT1 bladder tumours: Report from Medical Research Council Subgroup on superficial bladder cancer (Urological Cancer Working Party). Brit J Urol 1994;73(6):639-644.

Dr. J. Palou Redorta

Cartagena 340-350

08025 Barcelona España

E-mail: jpalou@fundacio-puigvert.es

(Trabajo recibido el 27 de diciembre 2004) 